\title{
The Role of Natural Gas in Indonesia CO2 Mitigation Action: The Environmental Kuznets Curve Framework
}

\author{
Dede Udayana Laksmana $^{\# 1}$, Uka Wikarya ${ }^{\# 2}$ \\ ${ }^{\#}$ Economic Planning and Development Policy, Faculty of Economics and Business, University of Indonesia, Jakarta, 10430, Indonesia \\ E-mail: ${ }^{\# l}$ udayana.dede@gmail.com
}

\begin{abstract}
Indonesia is one of the developing countries in the world, which is predicted to become one of the strongest economies in the world. Many challenges facing Indonesia, along with its economic growth, include energy security and environmental problems. These problems can be overcome simultaneously with the selection and allocation of appropriate energy sources. With the constraints of dependence on fossil energy, natural gas can be a "clean fossil energy" choice that can reduce $\mathrm{CO}_{2}$ emissions amid Indonesia's economic growth. Under the Environmental Kuznets Curve (EKC) framework and the ARDL to cointegration approach, this study estimates the long-term and short-term relationship between $\mathrm{CO}_{2}$ emissions and per capita GDP in three different models. The estimation results show that EKC in Indonesia is generally formed in the long term, but not in the electricity sector. The existence of EKC in Indonesia indicates the effects of energy conservation. The estimation results also show that natural gas consumption has a negative correlation with $\mathrm{CO}_{2}$ emissions in general. In the electricity sector, electricity from natural gas contributes to the smallest $\mathrm{CO}_{2}$ emissions. Empirical evidence from this study can then be used as a reference in the formulation of policies related to the energy mix and efforts to encourage increased domestic natural gas consumption.
\end{abstract}

Keywords - CO2 emissions; environmental Kuznets curve; Indonesia; natural gas; policy.

\section{INTRODUCTION}

Indonesia is one of the developing countries, which is predicted to become one of the strongest economies in the world. Indonesia's per capita GDP continues to increase, although it experienced a decline in 1998 due to the Asian Financial Crisis. This economic growth is followed by the increase in energy consumption, which is so common as energy is an important aspect that needed by a country in supporting its economic growth. However, economic growth in Indonesia also followed by an increase in $\mathrm{CO}_{2}$ emissions. This is inseparable from the composition of energy that supports the Indonesian economy. $\mathrm{CO}_{2}$ emissions come from fossil fuel consumption in which it is needed to convert as energy. Meanwhile, within 17 years (2000-2017), 96\% of Indonesia's energy composition was still dominated by fossil fuels. Renewable energy does not show a significant increase in that period. Therefore, that is why $\mathrm{CO}_{2}$ emissions continue to increase, along with Indonesia's energy consumption and economic growth (Figure 1).
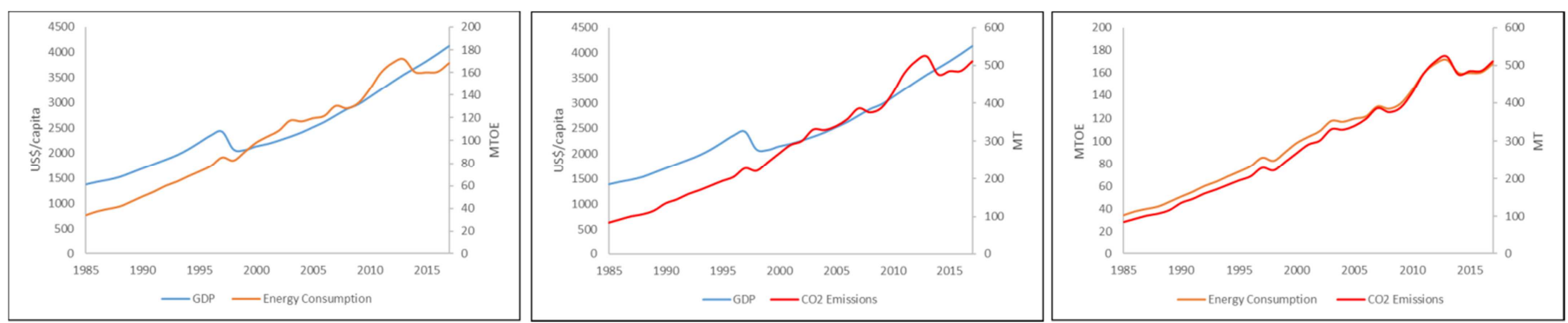

Fig. $1 \mathrm{GDP}$, energy consumption and $\mathrm{CO}_{2}$ emissions

$\mathrm{CO}_{2}$ emissions in Indonesia come from several sectors; forestry, energy, and agriculture. In 2017, $48 \%$ of $\mathrm{CO}_{2}$ emissions came from the forestry sector. Many deforestations in Indonesia cause this. However, in the longterm, when deforestation has stopped, the energy sector will be the most significant contributor to $\mathrm{CO}_{2}$ emissions in Indonesia. WRI estimates that $\mathrm{CO}_{2}$ emissions from the energy sector will surpass $\mathrm{CO}_{2}$ emissions from the forestry sector in 2027 [1]. That problem would happen if there were 
no changes in Indonesia's energy composition, as fossil fuel still dominated Indonesia's energy composition.

The increase in $\mathrm{CO}_{2}$ emissions brings harmful effects to the environment, such as erratic climate change and rising surface temperatures. This has become a serious concern of the world. On December 12, 2015, the Paris Agreement was established as a form of the world's response to this issue. The Indonesia Government joined in signing this agreement in 2016, and as a form of commitment, Nationally Determined Contribution (NDC) was established. The target to be achieved in reducing GHG emissions by $29 \%$ by selfeffort and $41 \%$ with international assistance by 2030 . In the energy sector, Indonesia is undertaking mitigation efforts in the National Energy Policy by changing the energy mix, increase low-emission or zero-emission energy, and reduce high-emission energy (Figure 2).

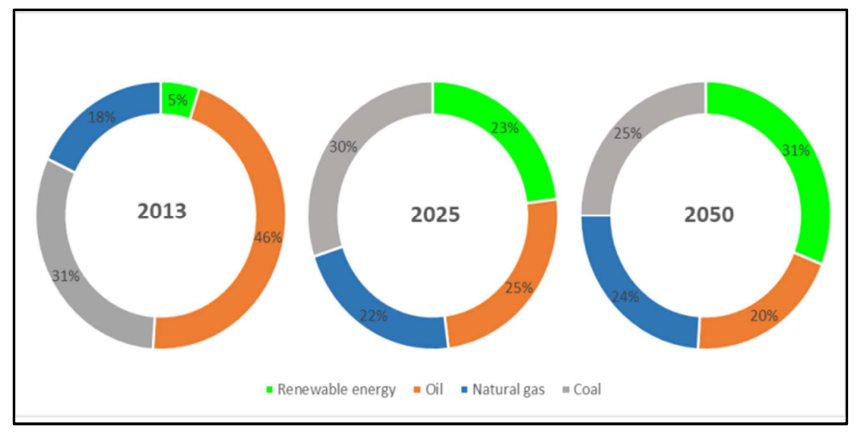

Fig. 2 Indonesia energy mix target

The energy that will be increased is natural gas and new renewable energy. Indonesia has enough energy from these two types of resources. However, the growth of renewable energy utilization itself is still low due to market mechanisms and regulations that are less attractive to investors. To be in line with the commitments that have been set, natural gas can be an opportunity. Natural gas is "clean" fossil energy where $\mathrm{CO}_{2}$ emissions are $50 \%$ lower than coal and oil [2]. In addition, proven reserves of natural gas in Indonesia are increasing along with the discovery of new preserves with vast reserves.

Unfortunately, Indonesia's domestic consumption is still low. $50 \%$ of the total utilization is allocated for LNG feed, which is intended as an export commodity. This has been going on for a long time because awareness of the advantages of using natural gas is still low, and the contract for buying and selling natural gas takes place over a long period; if terminated unilaterally, it would be a loss for Indonesia. Domestic use itself is dominated by the industrial sector $(25 \%)$ and the electricity sector $(10 \%)$, which is an essential sector in supplying Indonesia's energy needs (Figure 3.). This situation should be a concern because Indonesia must be prepared with cleaner energy to support economic growth while simultaneously improving the quality of the environment.

Comparing to other countries in the world, natural gas has become the potential energy in supporting the economy while maintaining the quality of its environment. The carbon price floor policy, which aims to increase the utilization of low-carbon technology, has a significant influence on increasing natural gas consumption in the UK in 2016 [3]. France uses natural gas as potential energy when closing 22 nuclear power plants. Japan also uses natural gas as energy after the Fukushima incident in 2011. China, a developing country with high economic growth, has encouraged an increase in natural gas consumption in the electricity sector through blue skies police.

- Top $=19 \mathrm{~mm}\left(0.75^{\prime \prime}\right)$

- Bottom = 28mm (1.1")

- Left = Right = $14.32 \mathrm{~mm}(0.56 ")$

$y$; policies that aim to improve air quality. From these examples, we have seen many countries in the world have chosen natural gas as an alternative energy source. Admittedly, energy consumption in Indonesia, which is still dependent on fossil energy, is a dilemma. On the one hand, this energy source is still the main choice in supporting the Indonesian economy because of slow renewable energy growth. On the other hand, the air quality is deteriorating due to increased $\mathrm{CO}_{2}$ emissions from the consumption of fossil fuels. However, this problem can be overcome by choosing the right energy source, namely natural gas. By increasing natural gas consumption, there is potential for economic growth in Indonesia not to be accompanied by an increase in environmental damage, which in this study is illustrated by an increase in $\mathrm{CO}_{2}$ emissions.

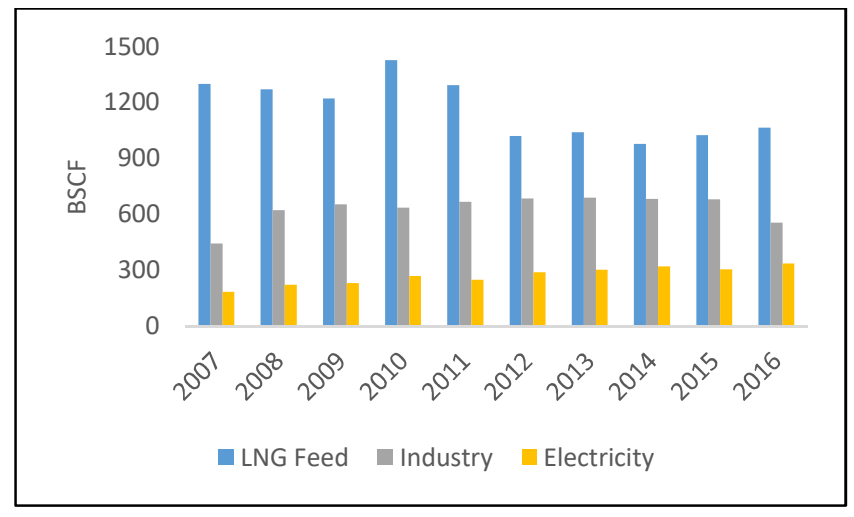

Fig. 3 Indonesia natural gas utilization

Economic growth will certainly have an impact on the environment. But the question is, is the impact good or bad? There is a theory known as the Environmental Kuznets Curve (EKC), which can help illustrate the relationship between economic growth and environmental quality. This theory states that environmental damage will increase at the beginning of economic growth and will decline at one point, along with economic growth [4]. The pattern formed from this relationship is an inverted U-pattern (Figure 4). The pattern formed is influenced by three factors.

Scale effect: this effect will be felt at the beginning of economic growth. At the beginning of economic growth, the country will focus on increasing output. The technology used is still traditional, land clearing is massive, and attention to the environment is still low. In this phase, environmental damage will increase. People with lowincome levels have not thought about ecological impacts. This effect is felt by low-income level countries.

The composition effect, which is the impact, is felt when there is a change in economic structure. As a country's per capita income increases, the structure of the economy also changes. The agricultural sector will slowly be reduced to being replaced by the industrial sector. At the beginning of 
this effect, environmental damage will increase. But it will gradually decrease with changes in input usage preferences. This happens because as per capita income rises, people are willing to pay more to get better environmental quality. This effect is felt in middle-income level countries.

Technique effect comprises the effect begins to be felt when there is a change in the type of technology used in economic activity. As the per capita income of a country getting higher, the willingness to pay for better environmental quality will getting higher also. This encourages many technological innovations, replacing old technology that intensively uses energy with new technologies that are more efficient and environmentally friendly. In this phase, the quality of the environment will improve, and the high-income level will felt this.

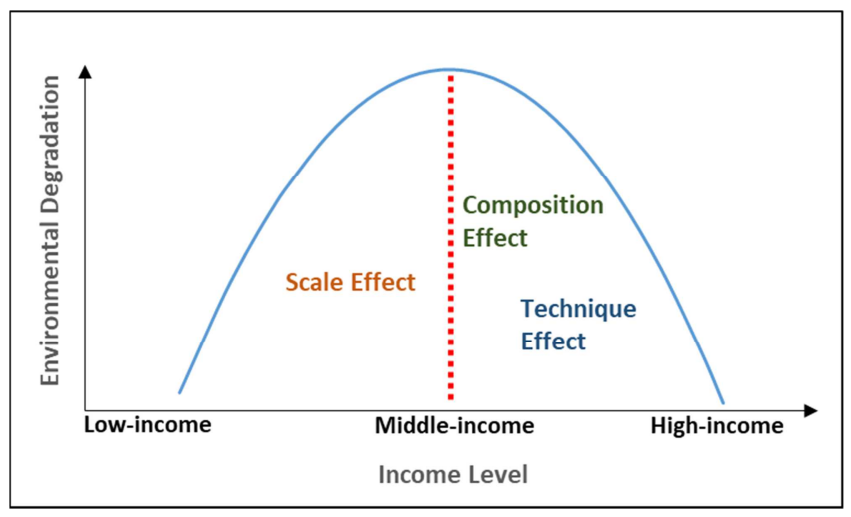

Fig. 4 Environmental Kuznets Curve

EKC is simply modeled in the quadratic function between per capita income and environmental indicators. The empirical model used for estimation is often written in natural logarithmic form. The aim is to facilitate interpretation and analysis because many ecological indicators that are obviously not worth zero or negative [5], [6], so it would be better to describe it in the growth rate. Simply put, the EKC model can be written:

$$
\ln E_{i t}=\beta_{0}+\beta_{1} \ln Y_{i t}+\beta_{2} \ln Y_{i t}^{2}++u_{i t}
$$

with $\ln E_{i t}$ is natural logarithmic per capita environmental indicator country $i$ at time $t, \ln Y_{i t}$ is natural logarithmic per capita income country $\mathrm{i}$ at time $\mathrm{t}$ and $\ln Y_{\mathrm{it}}^{2}$ is a natural logarithmic per capita income square country i at time t. Furthermore, the development of this model can be done by adding other explanatory variables to assist in the interpretation of the composition effect and technique effect. The model can be written:

$$
\ln E_{i t}=\beta_{0}+\beta_{1} \ln Y_{i t}+\beta_{2} \ln Y_{i t}^{2}+\ln X_{i t}+u_{i t}
$$

with $\ln X_{i t}$ is natural logarithmic for per capita explanatory variable (composition effect/technique effect) country i at time t.

EKC empirical studies on $\mathrm{CO}_{2}$ emissions have been carried out in several various studies. The earliest study was conducted by Shafik and Bandyopadhyay, where they did not find EKC in the relationship between $\mathrm{CO}_{2}$ emissions and global economic growth [7]. The absence of the EKC is caused by the phenomenon of a free rider, where differences in economic growth between countries cause differences in behavior in responding to $\mathrm{CO}_{2}$ emissions problems. This finding supported by Cole at al [5], which found that $\mathrm{CO}_{2}$ emissions at a global level increased over time, although those emissions decreased at a local level. To analyze the EKC more specifically in a country, subsequent studies were conducted with time-series data. The use of time-series data is chosen because the use of cross-country data is often constrained by homogeneity tests, which lead to biased estimation results [6]. Time-series data analysis helps analyze the EKC patterns of each country more specifically because it is aided by historical data.

Given that most of the $\mathrm{CO}_{2}$ emissions come from energy consumption, then this variable is often used as an explanatory variable. Whether it's panel data or time-series, increasing energy consumption will increase $\mathrm{CO}_{2}$ emissions [8]-[11]. This happens because of a higher share of fossil fuel in most of the countries' energy consumption. Most of the previous studies commonly employed energy consumption data at an aggregate level. It is essential to know which sector emitted more pollutants because each energy sub-sector issued different amounts of $\mathrm{CO}_{2}$ emissions. A more in-depth analysis will be easier to do if the energy consumption of each energy sub-sector is analyzed. It would be resulting in the EKC analysis to be more comprehensive.

Along with the development, many studies try to describe the types of energy consumed to get more in-depth analysis, one of which is often used is natural gas consumption. Natural gas is fascinating to analyze because it is said to be "clean fossil energy,"; which only produces $50 \%$ fewer emissions than other fossil energy. Many studies show that increasing natural gas consumption will reduce $\mathrm{CO}_{2}$ emissions levels, either significantly or not [12]-[14]. The insignificant results are often found in countries with low levels of natural gas consumption, while significant effects are shown in countries with high natural gas consumption [2], [15], [16].

Finally, several studies are investigated the relationship between economic growth and $\mathrm{CO}_{2}$ emissions in Indonesia within the framework of the EKC. Studies by Dong et al. [16] and Sugiawan and Managi [17] showed that the EKC pattern was formed in Indonesia. On the other hand, several studies show different results where the EKC is not existed in Indonesia [11], [18]. So far, there is only one study that investigates the effect of natural gas consumption in Indonesia within the EKC framework [16]. Yet this study was analyzed using panel data, and the result shows that increasing Indonesia's natural gas consumption has a negative impact on $\mathrm{CO}_{2}$ emissions.

In contrast to previous studies that discussed the existence of EKC in Indonesia, this study offers a novelty by explains EKC more precisely by adding a focus on the effect of natural gas consumption in the formation of the EKC in Indonesia. In addition, it is essential to analyze the impact of energy consumption in each sector, so this study examines how energy consumption in the electricity sector forms the EKC pattern in general and in the electricity sector itself. The electricity sector was chosen because besides being one of the largest natural gas consumers in Indonesia's energy sector, this sector is also the most significant contributor to $\mathrm{CO}_{2}$ emissions among the other energy sub-sectors. This 
study has three objectives; first, analyzing the existence of the EKC in Indonesia, second, explaining the presence of the EKC in Indonesia's electricity sector, and third, comparing the effect of using natural gas with other fossil fuels on the level of $\mathrm{CO}_{2}$ emissions in Indonesia.

\section{MATERIALS AND METHOD}

Economic activity produces products in its process, both in the form of primary products and by-products. $\mathrm{CO}_{2}$ emissions are one example of a by-product of economic activity. To analyze the relationship between these two, the basic EKC model is often used. More specifically, $\mathrm{CO}_{2}$ emissions can come from various sources, one of which is the energy sector. $\mathrm{CO}_{2}$ emissions from the energy sector are generated from the combustion of fossil fuels (coal, petroleum, and natural gas). Those kinds of fossil fuels produce $\mathrm{CO}_{2}$ emissions at different levels, in which the highest emissions are produced by coal, then followed by oil, and the lowest emissions come from natural gas. This could be an alternative in the dependence on fossil fuel, reduction in coal, and petroleum consumption, followed by the increase in natural gas consumption that will be able to reduce the rise in $\mathrm{CO}_{2}$ emissions from the energy sector. Therefore, to analyze the influence of coal, petroleum, and natural gas consumption on $\mathrm{CO}_{2}$ emissions together with an analysis of the existence of EKC in Indonesia, this study employed the basic EKC model with the addition of coal, petroleum, and natural gas consumption as other explanatory variables.

This study uses three types of quadratic models in the form of natural logarithmic to estimate and illustrate whether an EKC pattern exists between economic growth and the level of $\mathrm{CO}_{2}$ emissions in Indonesia. The differences between these three models are the scope of analysis in the energy sector level. The first model (FF model) depicts the relationship between total $\mathrm{CO}_{2}$ emissions from the energy sector with per capita GDP. The model also conducted analyzes the relationship between consumption of each type of fossil fuel in aggregate level and $\mathrm{CO}_{2}$ emissions. The model is written as:

$$
\begin{aligned}
\ln C \mathrm{O}_{2}=\alpha_{0} & +\alpha_{1} \ln G D P P_{t}+\alpha_{2} \ln G D P P^{2}{ }_{t} \\
& +\alpha_{3} \ln C C P_{t} \\
& +\alpha_{4} \ln O C P_{t}+\alpha_{5} \ln N G C P_{t}+u_{t}
\end{aligned}
$$

with ln $\mathrm{CO}_{2 \mathrm{t}}$ is natural logarithmic per capita $\mathrm{CO}_{2}$ emissions that comes from fossil fuel combustion at year $t$, $\ln \operatorname{GDPP}_{t}$ is natural logarithmic per capita GDP at year $t$, $\ln \mathrm{GDPP}_{\mathrm{t}}^{2}$ is natural logarithmic per capita GDP square at year $t$, $\ln \mathrm{CCP}_{\mathrm{t}}$ natural logarithmic per capita of coal consumption at year $t$, $\ln \mathrm{OCP}_{\mathrm{t}}$ is natural logarithmic per capita of oil consumption at year $t$, ln $\mathrm{NGCP}_{\mathrm{t}}$ is natural logarithmic per capita of natural gas consumption at year $\mathrm{t}$, and $\mathrm{u}_{\mathrm{t}}$ is standard error term.

The next two models conducted analyzes in the energy sub-sector scope. The electricity sector is the most significant contributor to $\mathrm{CO}_{2}$ emissions in the energy sector. To analyze the relationship between this sector and total $\mathrm{CO}_{2}$ emissions, the second model is used (Model EL-I). This model employee-generated electricity from fossil fuel as the proxy for fossil fuel consumption in the electricity sector due to the limitation of data availability; assuming the ratio between fossil fuel consumption in the electricity sector and generated electricity from fossil fuel is equal. The model is written as:

$$
\begin{aligned}
\ln C \mathrm{O}_{2} t=\alpha_{0}+ & \alpha_{1} \ln G D P P_{t}+\alpha_{2} \ln G D P P^{2}{ }_{t} \\
& +\alpha_{3} \ln E C O A L_{t} \\
& +\alpha_{4} \ln E O I L_{t}+\alpha_{5} \ln E N G A S_{t}+u_{t}
\end{aligned}
$$

with ln $\mathrm{CO}_{2 \mathrm{t}}$ is natural logarithmic per capita $\mathrm{CO}_{2}$ emissions that comes from fossil fuel combustion at year $t$, ln GDPP ${ }_{t}$ is natural logarithmic per capita GDP at year $t$, $\ln \mathrm{GDPP}^{2}{ }_{\mathrm{t}}$ is natural logarithmic per capita GDP square at year t, ln ECOAL $_{t}$ is natural logarithmic of electricity generated from coal at year $t$, ln EOIL $t$ is natural logarithmic per capita electricity generated from oil at year $t, \ln$ ENGAS $_{t}$ is natural logarithmic of electricity generated from natural gas at year $t$, and $\mathrm{u}_{\mathrm{t}}$ is standard error term.

Finally, the third model (Model EL-II) is a model that aims to analyze the existence of EKC in Indonesia's electricity sector in Indonesia. This model is proposed considering that most of Indonesia's economic activity is relying on electricity. As the economic growth over time, so does the demand for electricity will rise that pushing the generation of electricity. This would lead to increases in $\mathrm{CO}_{2}$ emissions from the electricity sector, as there is no significant change in the composition of electricity sources. This model employs $\mathrm{CO}_{2}$ emissions from the electricity sector as the dependent variable, and the model is written as:

$$
\begin{aligned}
\ln C \mathrm{O}_{2} E L_{t}=\alpha_{0} & +\alpha_{1} \ln \text { GDPP }_{t}+\alpha_{2} \ln G D P P^{2} \\
& +\alpha_{3} \ln E C O A L_{t} \\
& +\alpha_{4} \ln \text { EOIL }_{t} \\
& +\alpha_{5} \ln E N G A S_{t}+u_{t}
\end{aligned}
$$

with $\ln \mathrm{CO}_{2} \mathrm{EL}_{\mathrm{t}}$ is natural logarithmic per capita $\mathrm{CO}_{2}$ emissions from electricity at year $t, \ln \mathrm{GDPP}_{\mathrm{t}}$ is natural logarithmic per capita GDP at year $t, \ln \operatorname{GDPP}^{2}$ is natural logarithmic per capita GDP square at year $t, \ln \mathrm{ECOAL}_{t}$ is natural logarithmic of electricity generated from coal at year $t$, $\ln \mathrm{EOIL}_{\mathrm{t}}$ is natural logarithmic per capita electricity generated from oil at year $t$, $\ln$ ENGAS $_{t}$ is natural logarithmic of electricity generated from natural gas at year $t$, and $\mathrm{u}_{\mathrm{t}}$ is standard error term. Two hypotheses are formulated from those models:

- The EKC curve in Indonesia is formed if $\alpha 1>0$ and $\alpha 2$ $<0$, and both are statistically significant.

- Natural gas is the cleanest fossil energy if $\alpha_{5}<\alpha_{3}$ and $\alpha_{5}<\alpha_{4}$.

The data used in this study is time-series data within the period 1985-2017. Data for per capita GDPP comes from World Development Indicator. Data on $\mathrm{CO}_{2}$ emissions, fossil fuel consumption, and electricity generated from fossil fuels are sourced from the 2018 BP Statistical Review. The data then transformed into per capita units by dividing data for each variable with Indonesia's population data. Data on $\mathrm{CO}_{2}$ emissions from the electricity sector is obtained by calculating using equations:

$$
C \mathrm{O}_{2} E L_{i t}=C E C_{i} \times E L F F_{i t}
$$

with $\mathrm{CO}_{2} \mathrm{EL}_{\mathrm{it}}$ are $\mathrm{CO}_{2}$ emissions that produced from fossil fuels $\mathrm{i}$ at time $\mathrm{t}$ which measures in T/kap, $\mathrm{CEC}_{\mathrm{i}}$ is $\mathrm{CO}_{2}$ 
emissions coefficient fossil fuels $\mathrm{i}$ which measures in $\mathrm{kg}$ $\mathrm{CO}_{2}$ per $\mathrm{MWh}$ and $\mathrm{ELFF}_{\mathrm{it}}$ is electricity generated from fossil fuels $\mathrm{i}$ at time $\mathrm{t}$ which measures in MWh. CEC used in this study comes from the Intergovernmental Panel on Climate Change (IPCC) (Table 1). Data $\mathrm{GDPP}^{2}$ results from the quadratic form of GDPP. Descriptive statistics for the data are tabulated in Table 2.

TABLE I

CO2 EMISSION COEFFICIENT

\begin{tabular}{|l|l|}
\hline Fuel type & $\begin{array}{l}\mathbf{C O}_{2} \text { emission coefficient }(\mathbf{k g} \\
\left.\mathbf{C O}_{2} / \mathbf{M W h}\right)\end{array}$ \\
\hline Lignite & 363.6 \\
\hline Diesel & 266.76 \\
\hline Natural gas & 201.96 \\
\hline
\end{tabular}

The model estimation process is carried out in four steps. The first step is the unit-root test. Considering the data is time-series, it is vital to check whether the data is stationary or not. This study employs two methods for the unit-root analysis, Augmented Dicky-Fuller and Philips-Perron. The purpose is to check the consistency of the result of the test. The second step is to check whether there is cointegration between dependent and independent variables. This test is conducted using ARDL-bound testing of cointegration. This method is selected because of its advantage, such as effectively corrected the possibility of endogeneity from an explanatory variable, suitable for small size sample, does not require all the variables to be integrated in the same order, and simultaneously estimates long-run and short-run relationship. This method determines those three models in unrestricted error-correction (UREC) model as follows:

Model FF

$$
\begin{aligned}
\Delta \ln C O_{2}=\varphi_{0}+\sum_{i=1}^{p} & \varphi_{1 i} \Delta \ln C O_{2}+\sum_{t-i}^{q} \varphi_{2 i} \Delta \ln G D P P_{t-i} \\
& +\sum_{i=0}^{r} \varphi_{3 i} \Delta \ln \left(G D P P_{t-i}\right)^{2} \\
& +\sum_{i=0}^{s} \varphi_{4 i} \Delta \ln C C P_{t-i}+\sum_{i=0}^{t} \varphi_{5 i} \Delta \ln O C P_{t-i} \\
& +\sum_{i=0}^{u} \varphi_{6 i} \Delta \ln N G C P_{t-i}+\gamma_{1} \ln C O_{2 t-1} \\
& +\gamma_{2} \ln G D P P_{t-1}+\gamma_{3} \ln \left(G D P P_{t-1}\right)^{2} \\
& +\gamma_{4} \ln C C P_{t-1}+\gamma_{5} \ln O C P_{t-1} \\
& +\gamma_{6} \ln N G C P_{t-1}+\tau_{t}
\end{aligned}
$$

\section{Model EL-I}

$$
\begin{aligned}
& \Delta \ln C O_{2 t} \\
& =\varphi_{0} \\
& +\sum_{i=1}^{p} \varphi_{1 i} \Delta \ln C O_{2 t-i}+\sum_{i=0}^{q} \varphi_{2 i} \Delta \ln G D P P_{t-i} \\
& +\sum_{i=0}^{r} \varphi_{3 i} \Delta \ln \left(G D P P_{t-i}\right)^{2} \\
& +\sum_{i=0}^{s} \varphi_{4 i} \Delta \ln E C O A L_{t-i}+\sum_{i=0}^{t} \varphi_{5 i} \Delta \ln E O I L_{t-i} \\
& +\sum_{i=0}^{u} \varphi_{6 i} \Delta \ln E N G A S_{t-i}+\gamma_{1} \ln C O_{2_{t-1}}+\gamma_{2} \ln G D P P_{t-1} \\
& +\gamma_{3} \ln \left(G D P P_{t-1}\right)^{2}+\gamma_{4} \ln E C O A L_{t-1}+\gamma_{5} \ln E O I L_{t-1} \\
& +\gamma_{6} \ln E N G A S_{t-1}+\tau_{t}
\end{aligned}
$$

\section{Model EL-II}

$\Delta \ln \mathrm{CO}_{2} E L_{t}$

$=\varphi_{0}$

$+\sum_{i=1}^{p} \varphi_{1 i} \Delta \ln C O_{2} E L_{t-i}+\sum_{i=0}^{q} \varphi_{2 i} \Delta \ln G D P P_{t-i}$

$+\sum_{i=0}^{r} \varphi_{3 i} \Delta \ln \left(G D P P_{t-i}\right)^{2}$

$+\sum_{\substack{i=0 \\ u}}^{s} \varphi_{4 i} \Delta \ln E C O A L_{t-i}+\sum_{i=0}^{t} \varphi_{5 i} \Delta \ln E O I L_{t-i}$

$+\sum_{i=0}^{u} \varphi_{6 i} \Delta \ln E N G A S_{t-i}++\gamma_{1} \ln C O_{2} E L_{t-1}$

$+\gamma_{2} \ln G D P P_{t-1}+\gamma_{3} \ln \left(G D P P_{t-1}\right)^{2}+\gamma_{4} \ln E C O A L_{t-1}$

$+\gamma_{5} \ln E O I L_{t-1}+\gamma_{6} \ln E N G A S_{t-1}+\tau_{t}$

with $\varphi$ is short-run coefficient, and $\gamma$ is the long-run coefficient in the ARDL model. The cointegration test is conducted by calculating F-statistic from lagged levels of the variables. The null hypothesis for no long-run relationship is H0: $\quad \gamma 1=\gamma 2=\gamma 3=\gamma 4=\gamma 5=\gamma 6=0$, while the alternative explanation for the existence of the long-run relationship is H1: $\gamma 1 \neq \gamma 2 \neq \gamma 3 \neq \gamma 4 \neq \gamma 5 \neq \gamma 6 \neq 0$. The upper and lower critical values for the F-test are derived by Pesaran et al. [19]. To accommodate small sample sizes, the significant amount was updated later by Narayan [20]. The null hypothesis of no cointegration is rejected if the calculated F-statistic value exceeds the upper critical value. Before the cointegration test, it is vital to choose the optimum lag order for the UREC model. This study uses the Akaike Information Criterion (AIC) to select the optimal lag order for the model.

The third step, after found cointegration between the dependent and independent variable, the long-run relationship is estimated using the following equation:

Model FF

$$
\begin{aligned}
\ln C \mathrm{O}_{2}=\gamma_{0}+\sum_{i=1}^{p} & \gamma_{1 i} \ln C \mathrm{O}_{2 t-i}+\sum_{i=0}^{q} \gamma_{2 i} \ln G D P P_{t-i} \\
& +\sum_{i=0}^{r} \gamma_{3 i} \ln \left(G D P P_{t-i}\right)^{2} \\
& +\sum_{i=0}^{s} \gamma_{4 i} \ln C C P_{t-i}+\sum_{i=0}^{t} \gamma_{5 i} \ln O C P_{t-i} \\
& +\sum_{i=0}^{u} \gamma_{6 i} \ln N G C P_{t-i}+\tau_{t}
\end{aligned}
$$




$$
\begin{aligned}
& \ln C O_{2 t} \\
& =\gamma_{0} \\
& +\sum_{i=1}^{p} \gamma_{1 i} \ln C O_{2 t-i}+\sum_{i=0}^{q} \gamma_{2 i} \ln G D P P_{t-i} \\
& +\sum_{i=0}^{r} \gamma_{3 i} \ln \left(G D P P_{t-i}\right)^{2} \\
& +\sum_{i=0}^{s} \gamma_{4 i} \ln E C O A L_{t-i}+\sum_{i=0}^{t} \gamma_{5 i} \ln E O I L_{t-i} \\
& +\sum_{i=0}^{u} \gamma_{6 i} \ln E N G A S_{t-i}+\tau_{t}
\end{aligned}
$$

\section{Model EL-II}

$$
\begin{aligned}
& \ln C O_{2} E L_{t} \\
& =\gamma_{0} \\
& +\sum_{i=1}^{p} \gamma_{1 i} \ln C O_{2} E L_{t-i}+\sum_{i=0}^{q} \gamma_{2 i} \ln G D P P_{t-i} \\
& +\sum_{i=0}^{r} \gamma_{3 i} \ln \left(G D P P_{t-i}\right)^{2} \\
& +\sum_{i=0}^{s} \gamma_{4 i} \ln E C O A L_{t-i}+\sum_{i=0}^{t} \gamma_{5 i} \ln E O I L_{t-i} \\
& +\sum_{i=0}^{r} \gamma_{6 i} \ln E N G A S_{t-i}+\tau_{t}
\end{aligned}
$$

and the short-run relationship is estimated using the following equation:

Model FF

$$
\begin{aligned}
\Delta \ln C O_{2 t}=\varphi_{0}+\sum_{i=1}^{p} & \varphi_{1 i} \Delta \ln C O_{2}+\sum_{t-\mathrm{i}}^{q} \varphi_{2 i} \Delta \ln G D P P_{t-\mathrm{i}} \\
& +\sum_{i=0}^{r} \varphi_{3 i} \Delta \ln \left(G D P P_{t-\mathrm{i}}\right)^{2} \\
& +\sum_{\substack{s=0 \\
t}}^{s} \varphi_{4 i} \Delta \ln C C P_{t-\mathrm{i}} \\
& +\sum_{i=0}^{u} \varphi_{5 i} \Delta \ln O C P_{t-\mathrm{i}} \\
& +\sum_{i=0}^{u} \varphi_{6 i} \Delta \ln N G C P_{t-\mathrm{i}}+\sigma E C T_{t-1}+\tau_{t}
\end{aligned}
$$

Model EL-I

$$
\begin{aligned}
\Delta \ln C O_{2 t}=\varphi_{0}+\sum_{i=1}^{p} & \varphi_{1 i} \Delta \ln C O_{2 t-\mathrm{i}}+\sum_{i=0}^{q} \varphi_{2 i} \Delta \ln G D P P_{t-\mathrm{i}} \\
& +\sum_{i=0}^{r} \varphi_{3 i} \Delta \ln \left(G D P P_{t-\mathrm{i}}\right)^{2} \\
& +\sum_{i=0}^{s} \varphi_{4 i} \Delta \ln E C O A L_{t-\mathrm{i}} \\
& +\sum_{i=0}^{t} \varphi_{5 i} \Delta \ln E O I L_{t-\mathrm{i}} \\
& +\sum_{i=0}^{u} \varphi_{6 i} \Delta \ln E N G A S_{t-\mathrm{i}}+\sigma E C T_{t-1}+\tau_{t}
\end{aligned}
$$

Model EL-II

$$
\begin{aligned}
\Delta \ln C O_{2} E L_{t}=\varphi_{0}+ & \sum_{i=1}^{p} \varphi_{1 i} \Delta \ln C O_{2} E L_{t-i}+\sum_{i=0}^{q} \varphi_{2 i} \Delta \ln G D P P_{t-\mathrm{i}} \\
& +\sum_{i=0}^{r} \varphi_{3 i} \Delta \ln \left(G D P P_{t-\mathrm{i}}\right)^{2} \\
& +\sum_{i=0}^{s} \varphi_{4 i} \Delta \ln E C O A L_{t-\mathrm{i}} \\
& +\sum_{i=0}^{t} \varphi_{5 i} \Delta \ln E O I L_{t-\mathrm{i}} \\
& +\sum_{i=0}^{i} \varphi_{6 i} \Delta \ln E N G A S_{t-\mathrm{i}}+\sigma E C T_{t-1}+\tau_{t}
\end{aligned}
$$

with $\sigma$ is speed adjustment parameter, and $\mathrm{ECT}_{\mathrm{t}-1}$ is lagged error-correction term. $\mathrm{ECT}_{t-1}$ measures the speed of adjustment of endogen variables when there is a shock in equilibrium. The coefficient of a lagged error-correction term is expected negative value and statistically significant.

In the last step, some diagnostic such as serial correlation tests, functional forms test, normality test, and heteroscedasticity test is conducted to check the robustness of the model. This study also employed a CUSUM and CUSUMQ test to check the stability of the parameter.

\section{RESULTS AND DISCUSSION}

The results of data analysis begin with a unit-root test that analyses the stationarity of the data. In the second stage, the results of the cointegration test explain the existence of a long-term relationship between the dependent variable and the independent variable. In the third stage, the results of long-term and short-term estimation demonstrate the correlation between variables while answering the hypotheses that have been formulated. In the fourth stage, the diagnostic test reveals that the model used is suitable.

\section{A. Unit-root test}

The unit-root test shows that all variables are stationary on order one (first differences). So, from that, it can be concluded that all variables are integrated into order one, I (1). (Table 3).

\section{B. Cointegration test}

Before doing the cointegration test stage, the optimum lag selection is chosen by the Akaike Information Criterion (AIC) method. After that, a cointegration test with ARDLbound testing of cointegration was carried out. The cointegration test results show that the calculated F-statistic value exceeds the upper critical value. So, the null hypothesis of no cointegration can be rejected. It concludes that there's cointegration between the dependent variable and the independent variable (Table 4).

\section{Long-run and short-run Estimation}

The estimation results of the FF model and the EL-I model (Table 5) show that in the long-run, EKC has existed in Indonesia; ln GDPP coefficient is positive, the coefficient ln $\mathrm{GDPP}^{2}$ is negative, and both are statistically significant. These estimation results are supported by studies conducted by Dong et al. [16] and Sugiawan and Managi [17]. The plot results of the FF model and the EL-I model have almost the same shape (Figures 5 and 6). The plot of the estimation results of these two models shows that the EKC pattern in 
Indonesia is still at the initial stage of the turning point. The turning point that began to emerge is suspected as the result of energy conservation efforts, not changes in the energy mix. This can be explained by the pattern of energy intensity and the energy consumption mix in Indonesia.

TABLE II

DESCRIPTIVE STATISTICS

\begin{tabular}{|c|c|c|c|c|c|c|c|}
\hline Variable & Obs & Mean & Std. Dev. & Min & Max & Unit & Source \\
\hline $\mathrm{CO}_{2}$ & 33 & 1.30 & 0.49 & 0.51 & 2.08 & MT/cap & BP Statistical Review 2018 \\
\hline $\mathrm{CO}_{2} \mathrm{EL}$ & 33 & 0.12 & 0.08 & 0.02 & 0.27 & MT/cap & own calculation \\
\hline GDPP & 33 & 2488.46 & 775.19 & 1386.48 & 4130.66 & US\$/cap & World Development Indicator \\
\hline $\mathrm{GDPP}^{2}$ & 33 & 6775126 & 4233364 & 1922327 & 17100000 & $(\mathrm{US} \$ / \mathrm{cap})^{2}$ & own calculation \\
\hline $\mathrm{CCP}$ & 33 & $9.21 \mathrm{E}-08$ & 7.4E-08 & $5.45 \mathrm{E}-09$ & $2.26 \mathrm{E}-07$ & MTOE/cap & BP Statistical Review 2018 \\
\hline $\mathrm{OCP}$ & 33 & $2.43 \mathrm{E}-07$ & $5.39 \mathrm{E}-08$ & $1.37 \mathrm{E}-07$ & $3.14 \mathrm{E}-07$ & MTOE/cap & BP Statistical Review 2018 \\
\hline NGCP & 33 & $1.22 \mathrm{E}-07$ & $2.76 \mathrm{E}-08$ & $6.54 \mathrm{E}-08$ & $1.56 \mathrm{E}-07$ & MTOE/cap & BP Statistical Review 2018 \\
\hline ECOAL & 33 & 0.20 & 0.16 & 0.03 & 0.58 & $\mathrm{MWh} / \mathrm{cap}$ & BP Statistical Review 2018 \\
\hline EOIL & 33 & 0.07 & 0.02 & 0.04 & 0.12 & $\mathrm{MWh} / \mathrm{cap}$ & BP Statistical Review 2018 \\
\hline ENGAS & 33 & 0.13 & 0.08 & 0.01 & 0.24 & MWh/cap & BP Statistical Review 2018 \\
\hline
\end{tabular}

TABLE III

UNIT-ROOT TEST RESULTS

\begin{tabular}{|c|c|c|c|c|c|c|c|c|}
\hline \multirow{3}{*}{ Variable } & \multicolumn{4}{|c|}{ Augmented Dickey-Fuller (ADF) } & \multicolumn{4}{|c|}{ Philips-Perron (PP) } \\
\hline & \multicolumn{2}{|c|}{ Level } & \multicolumn{2}{|c|}{ First Differences } & \multicolumn{2}{|c|}{ Level } & \multicolumn{2}{|c|}{ First Differences } \\
\hline & No Trend & Trend & No Trend & Trend & No Trend & Trend & No Trend & Trend \\
\hline $\ln \mathrm{CO}_{2}$ & -2.494 & -1.036 & $-3.259 * *$ & $-4.164 * * *$ & $-3.299 * *$ & -0.861 & $-4.657 * * *$ & $-5.570 * * *$ \\
\hline $\ln \mathrm{CO}_{2} \mathrm{EL}$ & -2.377 & -1.942 & $-3.791 * * *$ & $-4.462 * * *$ & -1.933 & -1.287 & $-5.085 * * *$ & $-5.717 * * *$ \\
\hline $\ln$ GDPP & -0.325 & -2.136 & $-3.576 * * *$ & $-3.511 * *$ & -0.285 & -1.847 & $-4.013 * * *$ & $-3.942 * *$ \\
\hline $\ln \mathrm{GDPP}^{2}$ & -0.149 & -1.997 & $-3.569 * * *$ & $-3.515 * *$ & -0.070 & -1.726 & $-4.011 * * *$ & $-3.952 * *$ \\
\hline $\ln$ ECOAL & -1.166 & -2.350 & $-3.799 * * *$ & $-3.817 * *$ & -0.738 & -1.922 & $-4.618 * * *$ & $-4.663 * * *$ \\
\hline $\ln$ EOIL & -2.279 & -2.917 & $-4.508 * * *$ & $-4.446^{* * *}$ & -2.048 & -2.641 & $-5.388 * * *$ & $-5.359 * * *$ \\
\hline ln ENGAS & -2.089 & -1.298 & $-3.718 * * *$ & $-4.377 * * *$ & -1.953 & -0.886 & $-3.753 * * *$ & $-4.121 * * *$ \\
\hline $\ln \mathrm{CCP}$ & -2.418 & -1.822 & $-4.885 * * *$ & $-5.186 * * *$ & $-3.264 * *$ & -2.864 & $-6.330 * * *$ & $-7.200 * * *$ \\
\hline $\ln \mathrm{OCP}$ & -2.428 & -1.288 & $-3.632 * * *$ & $-4.654 * * *$ & $-3.036 * *$ & -1.259 & $-4.910 * * *$ & $-5.587 * * *$ \\
\hline $\ln \mathrm{NGCP}$ & $-2.782 *$ & -0.608 & $-2.677 *$ & $-4.243 * * *$ & $-2.895 * *$ & -0.627 & $-4.879 * * *$ & $-6.213 * * *$ \\
\hline
\end{tabular}

TABLE IV

COINTEGRATION TEST RESUlTS

\begin{tabular}{|l|l|l|l|l|}
\hline $\begin{array}{l}\text { Model } \\
\text { (Optimum lag) }\end{array}$ & \multicolumn{1}{|c|}{$\begin{array}{c}\text { FF } \\
(211002)\end{array}$} & $\begin{array}{c}\text { EL-I } \\
(211000)\end{array}$ & $\begin{array}{c}\text { EL-II } \\
(221201)\end{array}$ \\
\hline F-statistic & & $25.763 * * *$ & $4.809 * *$ & $45.522 * * *$ \\
\hline \multirow{3}{*}{$I(0)$} & $1 \%$ & 4.673 & 4.604 & 4.741 \\
\cline { 2 - 6 } & $5 \%$ & 3.167 & 3.158 & 3.175 \\
\cline { 2 - 6 } & $10 \%$ & 2.571 & 2.578 & 2.564 \\
\hline \multirow{3}{*}{$I(1)$} & $1 \%$ & 6.874 & 6.671 & 7.078 \\
\cline { 2 - 6 } & $5 \%$ & 4.808 & 4.719 & 4.897 \\
\cline { 2 - 6 } & $10 \%$ & 3.984 & 3.930 & 4.037 \\
\hline
\end{tabular}




\begin{tabular}{|l|l|l|l|}
\multicolumn{1}{c}{ LONG-RUN ESTIMATION } \\
\hline \multirow{2}{*}{ Variable } & \multicolumn{2}{c|}{ Quadratic Model } \\
\cline { 2 - 4 } & \multicolumn{1}{c|}{ FF } & \multicolumn{1}{c|}{ EL-I } \\
\hline $\ln$ GDPP & $3.791^{*}$ & & $14.742 * * *$ \\
\hline $\ln$ GDPP & $-0.240^{*}$ & & $-0.952^{* * *}$ \\
\hline $\ln \mathrm{CCP}$ & $0.215^{* * *}$ & & \\
\hline $\ln \mathrm{OCP}$ & $0.677^{* * *}$ & & \\
\hline $\ln \mathrm{NGCP}$ & -0.149 & & \\
\hline $\ln$ ECOAL & & & $0.329 * * *$ \\
\hline $\ln$ EOIL & & & 0.028 \\
\hline $\ln$ ENGAS & & & -0.029 \\
\hline Constant & $-13.503 *$ & $-56.208^{* * *}$ \\
\hline R-squared & 0.923 & & 0.687 \\
\hline Adj R-squared & 0.879 & & 0.553 \\
\hline
\end{tabular}

\begin{tabular}{|l|l|l|l|}
\multicolumn{4}{|c}{ SHORT-RUN ESTIMATION } \\
\hline \multirow{2}{*}{ Variable } & \multicolumn{2}{|c|}{ Quadratic Model } \\
\cline { 2 - 4 } & \multicolumn{1}{|c|}{$\mathrm{FF}$} & \multicolumn{1}{c|}{ EL-I } \\
\hline$\Delta \ln \mathrm{CO}_{2_{t-i}}$ & 0.060 & & 0.173 \\
\hline$\Delta \ln \mathrm{GDPP}$ & $-40.031^{* *}$ & & $-74.731^{* *}$ \\
\hline$\Delta \ln \mathrm{GDPP}{ }^{2}$ & $2.599^{* *}$ & & $4.862^{* *}$ \\
\hline$\Delta \ln \mathrm{CCP}$ & $0.201^{* * *}$ & & \\
\hline$\Delta \ln \mathrm{OCP}$ & $0.635^{* * *}$ & & \\
\hline$\Delta \ln \mathrm{NGCP}$ & $0.131^{*}$ & & \\
\hline$\Delta \ln \mathrm{ECOAL}$ & & & $0.279^{* * *}$ \\
\hline$\Delta \ln \mathrm{EOIL}$ & & & 0.024 \\
\hline$\Delta \ln \mathrm{ENGAS}$ & & & -0.025 \\
\hline ECT & & & $-0.846^{*}-1 *$ \\
\hline Constant & $-12.664^{*}$ & & $-47.546^{* * *}$ \\
\hline
\end{tabular}

Statistically significant at $* * * 1 \%, * * 5 \%$, and $* 10 \%$

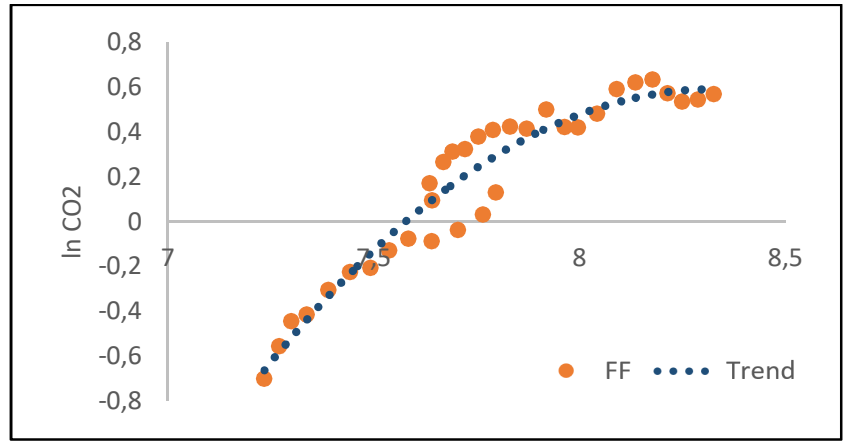

Fig. 5 Model FF estimation plot

Over the past three decades, fossil energy still dominates the energy mix in Indonesia, and the amount of consumption continues to increase. The combination of energy consumption in Indonesia is still dominated by coal and oil, two fossil energy with very high emission coefficient levels. The use of these two-fossil energy continues to increase in the long run. Meanwhile, natural gas consumption in Indonesia has not undergone significant changes and tends to move horizontally. This increase in the consumption of

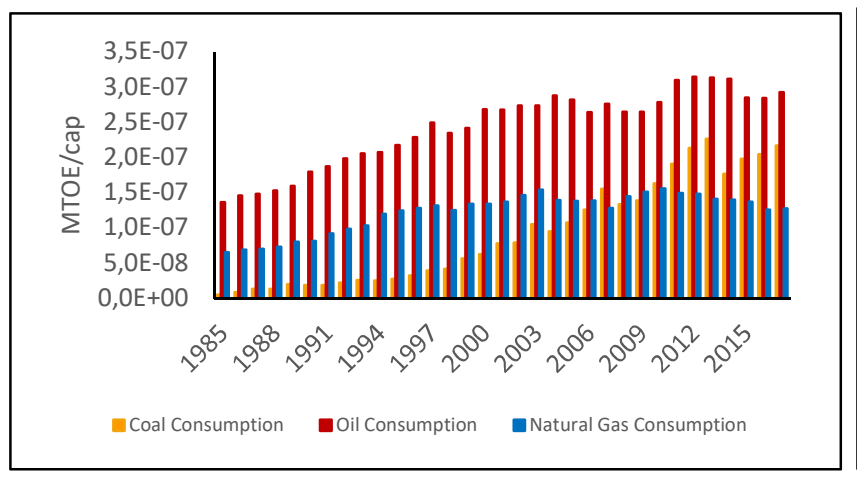

Fig. 7 Fossil fuel consumption

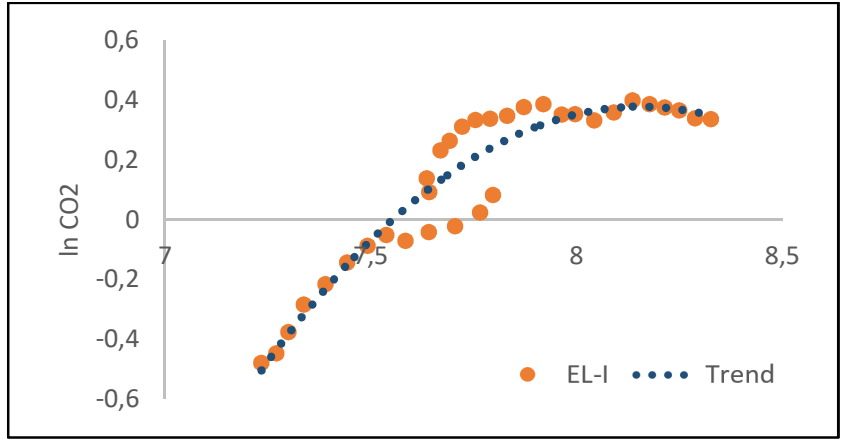

Fig. 6 Model EL-I estimation plot

two types of fossil fuels has significant implications for increasing $\mathrm{CO}_{2}$ emissions in Indonesia (Figure 7).

On the other hand, the level of fossil energy intensity in Indonesia begins to decline. The power of fossil energy in Indonesia increase at the beginning and then slowly decline (Figure 8). Along with the decline of fossil energy intensity, the concentration of $\mathrm{CO}_{2}$ emissions also shows the same pattern (Figure 9). This indicates that efforts of conservation energy in Indonesia have showing results.

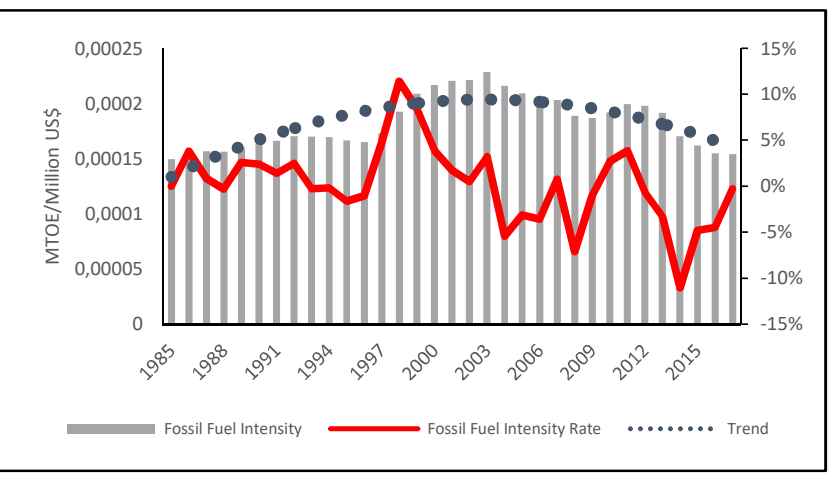

Fig. 8 Fossil fuel intensity 
It is adjusted to the EKC theory; the turning point of the EKC pattern in Indonesia is caused by the technique effect, which is characterized by the decreasing energy intensity. The composition effect has not shown any influence in shaping the EKC, as there is no change in the energy mix.

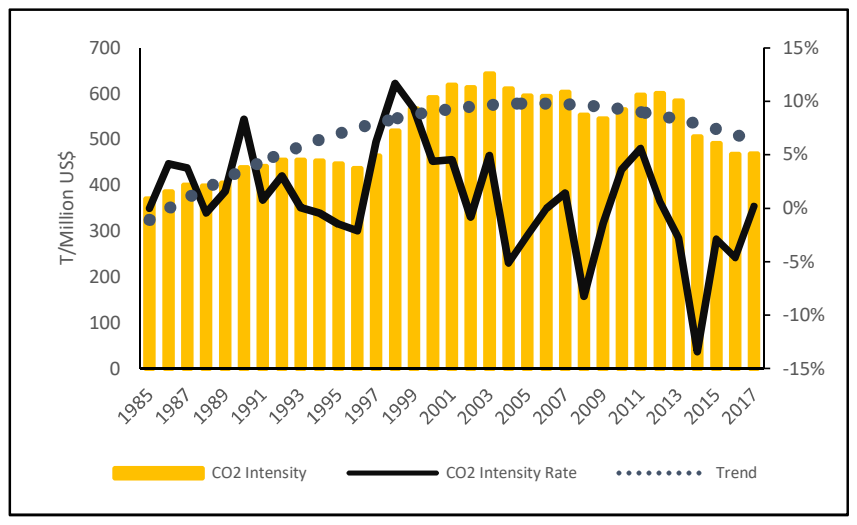

Fig. $9 \mathrm{CO}_{2}$ emission intensity

The long-term and short-term estimation results for energy variables in these two models have the same direction. The FF model shows that oil consumption is the most significant contributor to $\mathrm{CO}_{2}$ emissions. This is supported by the fact that $46 \%$ of fossil energy consumption in Indonesia is oil. In aggregate, oil is the biggest contributor because most of these sectors consume fuel. Coal is the second-largest contributor to emissions because most of this fuel is overwhelmed in the electricity sector, while the rest is consumed in the industrial area. Although coal is only consumed in two industries, the amount of consumption exceeds the amount of natural gas consumption, in which natural gas is destroyed by a more diverse sector compared to coal. In addition, emissions resulting from coal combustion are far higher than natural gas. The increase in natural gas consumption itself is proven empirically to reduce $\mathrm{CO}_{2}$ emissions levels. But the effect is not so significant because natural gas consumption is only $20 \%$ of the total use of fossil fuels. In addition, natural gas consumption has not changed much over the past three decades.

The estimation results for the FF model energy variables can be compared with the EL-I model. In the EL-I model, electricity generated from coal is the most significant contributor to $\mathrm{CO}_{2}$ emissions. This is a consequence as the highest coal consumption occurs in the electricity sector. While electricity production from oil also has a positive effect on increasing $\mathrm{CO}_{2}$ emissions, but it resulted in lower $\mathrm{CO}_{2}$ emissions than coal and not so significant. This is because the consumption of oil in the electricity sector has begun to be reduced. Electricity production from oil is only $10 \%$ of the total electricity produced by fossil fuels. The results of this estimation model also show that electricity production from natural gas has a negative effect on the growth of total $\mathrm{CO}_{2}$ emissions. However, this effect is not significant because electricity generated from natural gas is only $23 \%$ of the total electricity produced by fossil fuels. This amount is too low when compared to electricity produced from coal, which is $67 \%$. From these two models, it can be concluded that the existence of the EKC in Indonesia is shaped by the scale effect and the technique effect. The composition effect has not contributed to the presence of the EKC in Indonesia, as it shows from coal and oil consumption, which continues to increase, while natural gas consumption has not changed much.

Estimated results (Table 6) and estimation plots of EL-II models indicate that EKC has not existed in the electricity sector (Figure 10). This shows that there has been no change in the composition of energy in the electricity sector, or the technology used in power plants in Indonesia is still conventional.

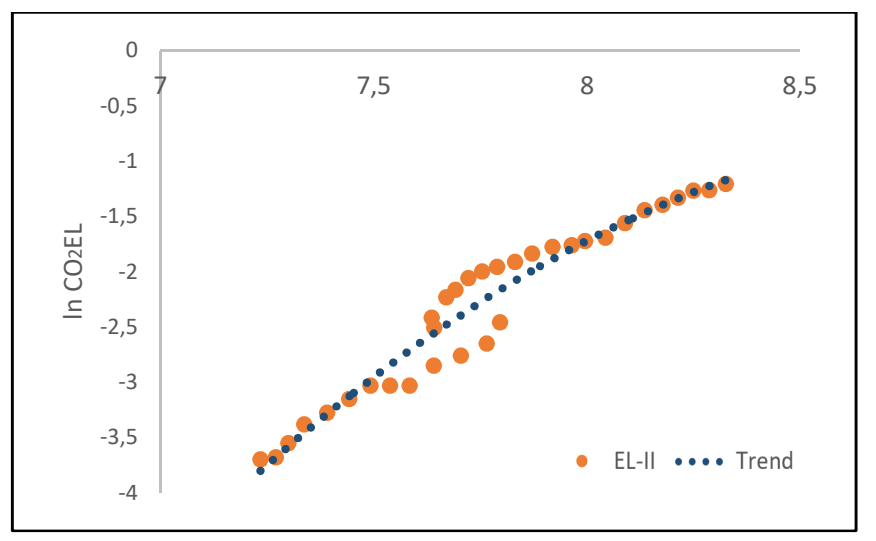

Fig. 10 Model EL-II estimation plot

Electricity in Indonesia is still dominated by electricity from coal-fired plants. When compared with electricity from oil and gas, the increase in electricity production from coal has increased very sharply. Electricity produced from oil and natural gas tends not to change much (Figure 11). This has implications for increasing $\mathrm{CO}_{2}$ emissions from the electricity sector in Indonesia. The intensity of $\mathrm{CO}_{2}$ emission

TABLE VI

MODEL EL-II LONG-RUN AND SHORT-RUN ESTIMATION (DEPENDENT VARIABLE: LN CO2EL) LONG-RUN ESTIMATION

\begin{tabular}{|c|c|c|c|}
\hline \multicolumn{2}{|c|}{ LONG-RUN ESTIMATION } & \multicolumn{2}{|c|}{ SHORT-RUN ESTIMATION' } \\
\hline \multirow{2}{*}{ Variable } & Quadratic Model & \multirow{2}{*}{ Variable } & Quadratic Model \\
\hline & EL-II & & EL-II \\
\hline $\ln$ GDPP & 2.043 & $\Delta \ln \mathrm{CO}_{2} \mathrm{EL}_{\mathrm{t}-1}$ & -0.174 \\
\hline $\ln \mathrm{GDPP}^{2}$ & -0.109 & $\Delta \ln$ GDP & 16.961 \\
\hline $\ln$ ECOAL & $0.573 * * *$ & $\Delta \ln \mathrm{GDP}^{2}$ & -1.099 \\
\hline $\ln$ EOIL & $0.166^{* * *}$ & $\Delta \ln$ ECOAL & $0.603 * * *$ \\
\hline ln ENGAS & $0.109 * * *$ & $\Delta \ln \mathrm{EOIL}$ & $0.161^{* * * *}$ \\
\hline Constant & -9.772 & $\Delta \ln$ ENGAS & $0.082^{* * * *}$ \\
\hline R-squared & 0.977 & ECT t-1 & $-0.971 * * *$ \\
\hline Adj R-squared & 0.959 & Constant & -9.494 \\
\hline
\end{tabular}


in the electricity sector also showed an increase (Figure 12). This indicates that the technology used in power plants in Indonesia has not shown efficiency efforts. From the EKC theory, the scale effect still dominates in influencing the pattern formed. This is illustrated by electricity production from coal, which continues to increase, and electricity production from oil and gas tends to be constant. In addition, the intensity of $\mathrm{CO} 2$ emissions in the electricity sector continues to increase. The analysis shows composition, and the technique effect has not shown its influence in shaping the EKC pattern in the electricity sector in Indonesia.

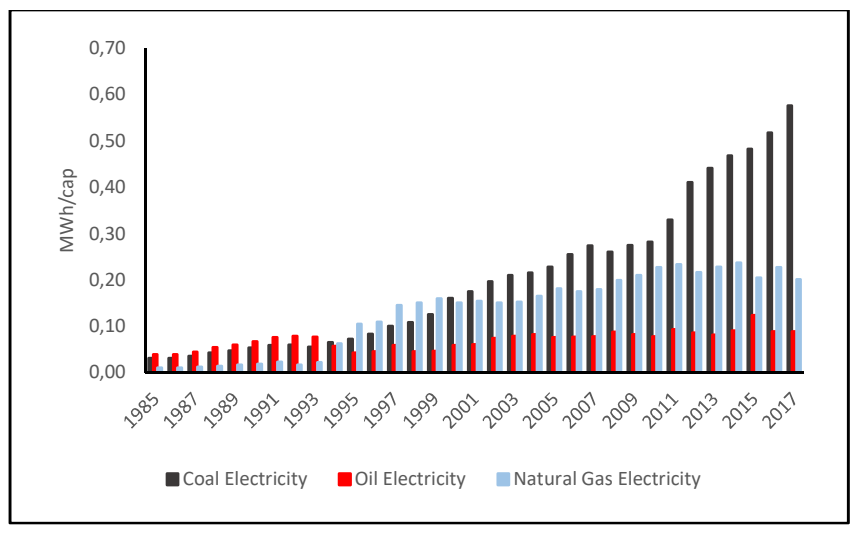

Fig. 11 Fossil fuel electricity production

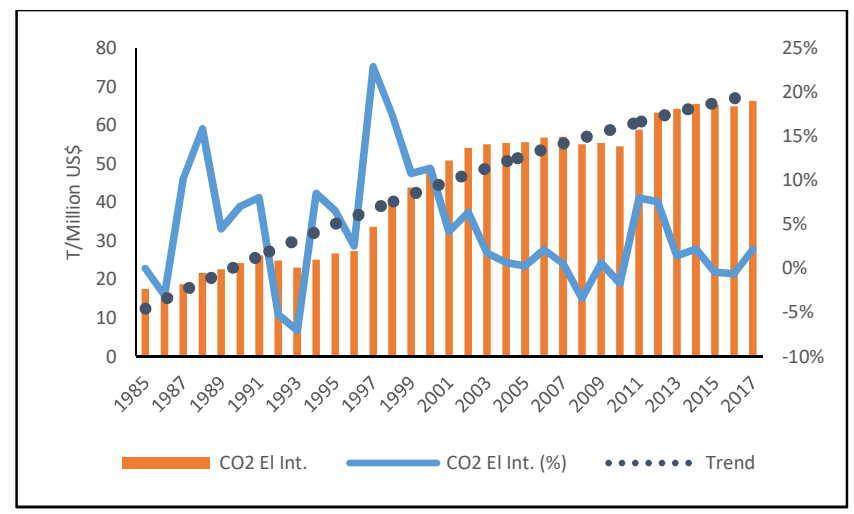

Fig. 12 The intensity of electricity $\mathrm{CO}_{2}$ emissions
The estimation results of this model also show that electricity produced from fossil fuels has a positive and significant relationship on the increase in $\mathrm{CO}_{2}$ emissions in this sector. Electricity generated from coal is the most significant contributor to emissions, while the lowest emissions are contributed by electricity generated from natural gas. The differences value shown is too wide, where an increase of $1 \%$ in coal electricity production will cause an increase in $\mathrm{CO}_{2}$ emissions in the electricity sector from $0.57 \%$. While the increase in electricity production from natural gas by $1 \%$ only increases $\mathrm{CO}_{2}$ emissions in the electricity sector by $0.10 \%$. Electricity production from oil is the second largest contributor to $\mathrm{CO}_{2}$ emissions in this sector. Although electricity produced from oil is smaller than that produced from natural gas, oil produces more $\mathrm{CO}_{2}$ emissions than natural gas.

Comparing EL-I and EL-II models, which both use the control variable of electricity production from fossil fuels, it can be said that the technique effect on the electricity sector has not shown a contribution to reducing $\mathrm{CO}_{2}$ emissions in Indonesia. This indicates that the efficiency that influenced the EKC in Indonesia came from other energy sub-sector outside the electricity sector. The rest, the composition effect still does not seem to contribute to the formation of the EKC pattern based on these two models. Short-run estimation results in Table 5, and 6 shows the coefficients of lagged error-correction terms $\left(\mathrm{ECT}_{\mathrm{t}-1}\right)$ in those three models have a negative sign and statistically significant. Their absolute value is quite high, indicating that there is a high speed of adjustment to make it back into equilibrium aftershock.

In the last step, the diagnostic test shows that there is no serial correlation, non-normality, and heteroscedasticity. The functional form test also shows there are no missspecifications in the model (Table 7). The stability parameter test shows that ARDL parameters are stable over the period (Figure 13). It shows by the statistic value of CUSUM and CUSUMQ (red line) for those models are within critical bounds (green line) at $5 \%$ significant.

TABLE VII

DIAGNOSTIC TEST RESUlts

\begin{tabular}{|l|l|l|l|l|l|}
\hline \multirow{2}{*}{ Diagnostic test } & \multicolumn{3}{|c|}{ Quadratic Model } & \multicolumn{1}{c|}{ EL-II } \\
\cline { 2 - 5 } & \multicolumn{1}{|c|}{ FF } & & \multicolumn{2}{|c|}{ EL-I } & 1.791 \\
\hline Serial correlation & 1.183 & & 0.614 & $(\mathrm{P}=0.181)$ \\
\hline Functional form & $(\mathrm{P}=0.277)$ & & $(\mathrm{P}=0.433)$ & 0.38 & 1.40 \\
\hline & 3.2 & & $(\mathrm{P}=0.771)$ & $(\mathrm{P}=0.283)$ \\
\hline Normality & $(\mathrm{P}=0.052)$ & & 0.057 & 4.073 \\
\hline & 0.456 & & $(\mathrm{P}=0.972)$ & $(\mathrm{P}=0.131)$ \\
\hline Heteroscedasticity & $(\mathrm{P}=0.796)$ & & 31.00 & 31.00 \\
\hline & 31.00 & & $(\mathrm{P}=0.415)$ & & $(\mathrm{P}=0.415)$ \\
\hline
\end{tabular}



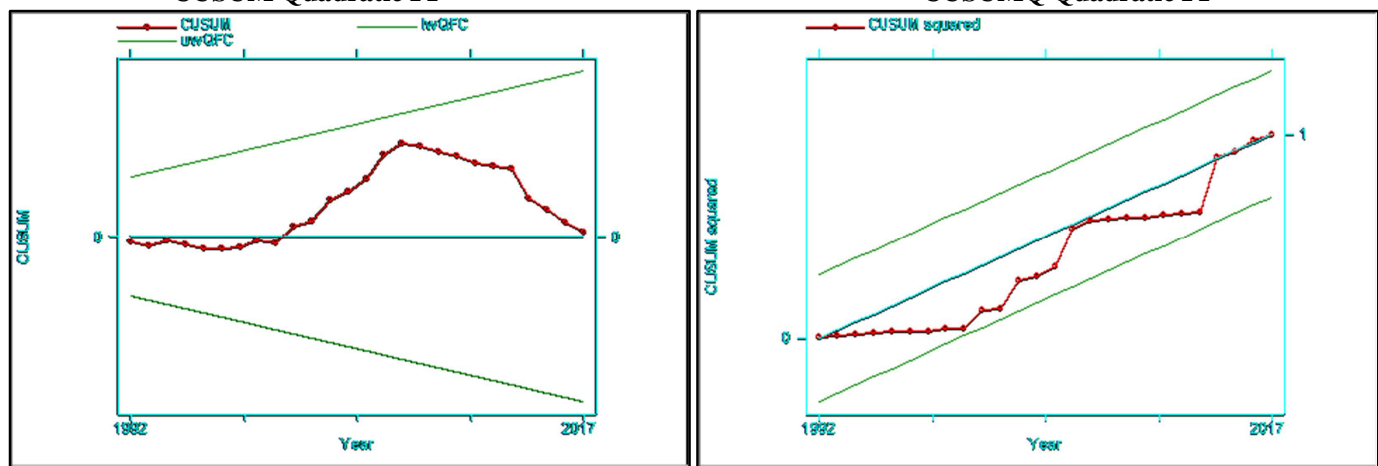

CUSUM Quadratic EL-I

CUSUMQ Quadratic EL-I
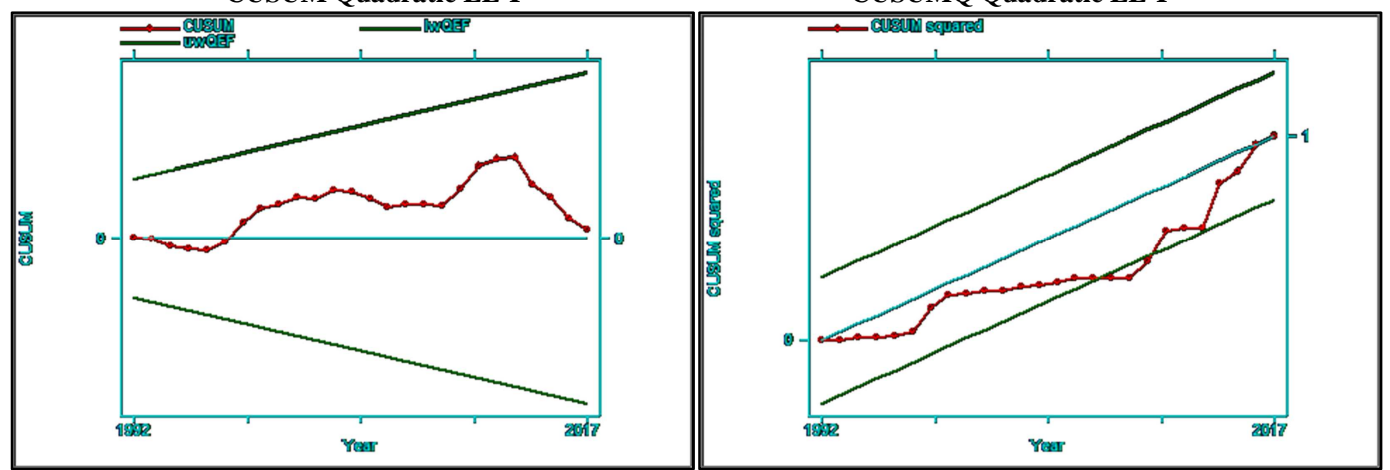

CUSUM Quadratic EL-II

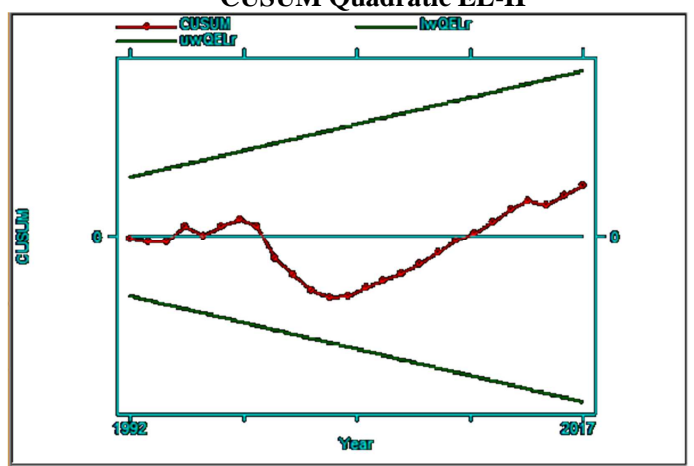

CUSUMQ Quadratic EL-II

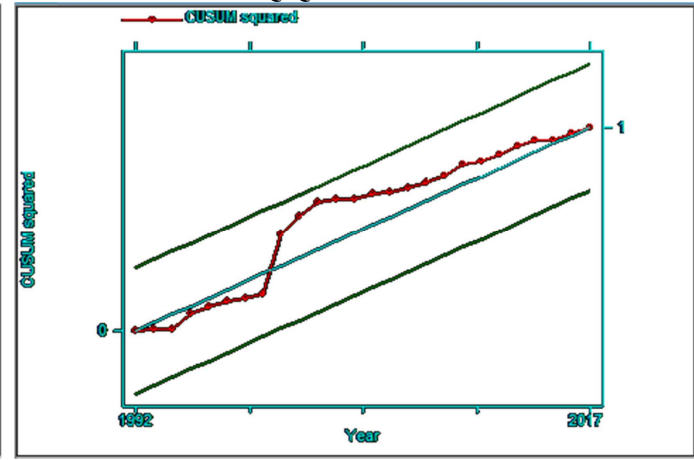

Fig. 13 CUSUM and CUSUMQ plot Model FF, EL-I and EL-II.

\section{CONCLUSIONS}

Indonesia is one of the developing countries in the world with a high level of economic growth. This economic growth is followed by increased consumption energy. On the other hand, Indonesia's environmental degradation also shows an increase along with the growth of the Indonesian economy, one of which is an increase in $\mathrm{CO}_{2}$ emissions. The economy of a country will indeed influence the quality of its environment, and this is illustrated in the Environmental Kuznets Curve pattern. This study was conducted to see whether the EKC has existed in the Indonesia energy sector. It is important to know how Indonesia's economic growth and its fossil energy consumption affect the level of $\mathrm{CO}_{2}$ emissions. The results of the study show that, generally, EKC existed in Indonesia. The existence of EKC indicates an energy conservation effort, depicted by the decrease in energy intensity followed by a decrease in the intensity of $\mathrm{CO}_{2}$ emissions. However, the EKC existed in Indonesia is still in the early stages. It is a consequence of no change in the energy mix; Indonesia's energy mix is still dominated by fossil energy.

In the electricity sector itself, EKC does not exist. This is because fossil fuels still dominate the energy source of this sector. In addition, the intensity of $\mathrm{CO}_{2}$ emissions in this sector is still increasing, which indicates that there are no energy conservation efforts in this sector. Besides, this indicates that the technology used in electricity generation in Indonesia has not shown efficiency efforts. This study proves empirically that natural gas is "clean fossil energy." This is evidenced by natural gas consumption has a negative effect on $\mathrm{CO}_{2}$ emissions. Unfortunately, the influence is not significant due to the low consumption of natural gas in Indonesia.

From this study, $\mathrm{CO} 2$ emissions in Indonesia can go down in two ways; the changes in the energy mix and increased energy conservation efforts. From these two alternatives, energy conservation efforts have shown results. However, this alternative might be more effective if it is supported by the utilization of an energy mix with low emission levels. Amid the high discovery of natural gas reserves and its 
superiority as "clean fossil energy," natural gas can be an alternative in the energy mix in Indonesia. In the future, natural gas consumption should be prioritized for domestic energy security. For this reason, the policy of reallocating the use of natural gas needs to be applied.

In the electricity sector itself, the use of natural gas should be a priority. The electricity sector is the highest contributor to $\mathrm{CO}_{2}$ emissions from the energy sector and will continue to increase in the future if coal is still the main energy source. This increase in emissions cannot be denied because electricity demand will continue to increase along with economic growth in Indonesia. However, this can be avoided by increasing natural gas consumption and reducing coal consumption in this sector. More specifically, in addition to policies related to changing the energy mix in the electricity sector, policies are also needed to encourage the implementation of more efficient electricity generation technologies. These two things can be done simultaneously by increasing the development of PLTGU, which has advantages in the form of efficiency compared to other plants.

In the future, this study can still be developed. As a follow-up and to complement this study, a study of costeffectiveness in any mitigation effort that utilizes natural gas can be done. The study can be in the form of:

- Comparing cost-effectiveness from increasing the construction of gas-fired power plants to increase the construction of coal-fired power plants.

- Comparing cost-effectiveness from the construction of natural gas-fired power plants with power plants equipped with carbon capture technology.

\section{ACKNOWLEDGMENT}

We express our gratitude to anonymous reviewers for their attention, helpful reviews, insight, and comments for this study.

\section{REFERENCES}

[1] A. Wijaya et al., "How Can Indonesia Achieve Its Climate Change Mitigation Goal? An Analysis of Potential Emissions Reductions from Energy and Land-use Policies”, 2017.
[2] K. Dong, R. Sun, G. Hochman, X. Zeng, H. Li, and H. Jiang, "Impact of natural gas consumption on $\mathrm{CO} 2$ emissions: Panel data evidence from China's provinces," J. Clean. Prod., 2017.

[3] D. Hirst, "Carbon Price Floor (CPF) and the price support mechanism," 2018.

[4] S. Dinda, "Environmental Kuznets Curve hypothesis: A survey," Ecol. Econ., 2004.

[5] M. A. Cole, A. J. Rayner, and J. M. Bates, "The environmental Kuznets curve: An empirical analysis," Environ. Dev. Econ., 1997.

[6] C. Lieb, "The Environmental Kuznets Curve - A Survey of the Empirical Evidence and of Possible Causes," Discuss. Pap. Ser., 2002.

[7] N. Shafik and S. Bandyopadhyay, "Economic growth and environmental quality: time series and cross-country evidence," Policy Res. Work. Pap. Ser., 1992.

[8] A. Jalil and S. F. Mahmud, "Environment Kuznets curve for CO2 emissions: A cointegration analysis for China," Energy Policy, 2009.

[9] H. Heidari, S. Turan Katircioğlu, and L. Saeidpour, "Economic growth, $\mathrm{CO} 2$ emissions, and energy consumption in the five ASEAN countries," Int. J. Electr. Power Energy Syst., 2015.

[10] M. G. B. and A. P. I, "International Journal of Management Research and Review," vol. 4, no. 1, pp. 316-334, 2014.

[11] B. Saboori and J. Sulaiman, "CO2 emissions, energy consumption and economic growth in the association of Southeast Asian Nations (ASEAN) countries: Acointegration approach," Energy, 2013.

[12] K. Dong, R. Sun, and X. Dong, "CO2 emissions, natural gas, and renewables, economic growth: Assessing the evidence from China," Sci. Total Environ., 2018.

[13] R. Li and M. Su, "The role of natural gas and renewable energy in curbing carbon emission: a Case study of the United States," Sustain., 2017.

[14] M. A. Zambrano-Monserrate, C. A. Silva-Zambrano, J. L. DavalosPenafiel, A. Zambrano-Monserrate, and M. A. Ruano, "Testing environmental Kuznets curve hypothesis in Peru: The role of renewable electricity, petroleum, and dry natural gas," Renewable and Sustainable Energy Reviews. 2018.

[15] K. Dong, R. Sun, and G. Hochman, "Do natural gas, and renewable energy consumption leads to less $\mathrm{CO} 2$ emission? Empirical evidence from a panel of BRICS countries," Energy, 2017.

[16] K. Dong, R. Sun, H. Li, and H. Liao, "Does natural gas consumption mitigate $\mathrm{CO} 2$ emissions: Testing the environmental Kuznets curve hypothesis for 14 Asia-Pacific countries," Renewable and Sustainable Energy Reviews. 2018.

[17] Y. Sugiawan and S. Managi, "The environmental Kuznets curve in Indonesia: Exploring the potential of renewable energy," Energy Policy, 2016.

[18] P. K. Narayan and S. Narayan, "Carbon dioxide emissions and economic growth: Panel data evidence from developing countries," Energy Policy, 2010.

[19] M. H. Pesaran, Y. Shin, and R. J. Smith, "Bounds testing approaches to the analysis of level relationships," J. Appl. Econom., 2001.

[20] P. K. Narayan, "The saving and investment nexus for China: Evidence from cointegration tests," Appl. Econ., 2005. 